\title{
Improving Students' Perception Towards Learning Mathematics: Impact of Teaching Application of Mathematics Fauziah Kasmin, ${ }^{1 *}$ Zuraini Othman, ${ }^{1}$ and Sharifah Sakinah Syed Ahmad ${ }^{1}$
}

\author{
${ }^{1}$ Department of Intelligent Computing and Analytics, Faculty of Information and Communications \\ Technology, Universiti Teknikal Malaysia Melaka, 76100, Durian Tunggal, Melaka, Malaysia. \\ *Corresponding author: fauziah@utem.edu.my \\ DOI: https://doi.org/10.37134/ejsmt.vol6.1.4.2019
}

Received: 13 May 2019; Accepted: 15 June 2019; Published: 25 June 2019

\begin{abstract}
Numerous decisions in our daily lives require the ability to calculate, solve problems, and employ concepts and skills in mathematics. However, students always have bad perceptions in mathematics as this subject is often challenging for students to master. Reports on issues about students' mathematical education have been raised by many mathematics educators. Among of the issues are about difficulties in understanding mathematical concepts, attitudes towards mathematics, low achievement in mathematics and many more. Hence, the aim of this study is to explore students' perceptions and attitudes towards mathematics by analyzing the impact of teaching application of mathematics to the students. The data were collected from Computer Science students where each participant was assigned to complete self-reported and close ended questionnaire. In this study, examination on attitudes of student include engagement, confidence and importance of mathematics. Data were analyzed by measuring the difference of individual statements on percentage of agreeing in pre - Smart for mathematics and post - Smart for mathematics. The findings show that when students learned and exposed to the application of mathematics, their engagement, confidence and importance of mathematics increases. It can be concluded that by exposing students the purpose of learning mathematics in computer science, students' positive attitude towards mathematics can be developed and hence improve their interests in learning mathematics.
\end{abstract}

Keywords applications of mathematics; students' perception; mathematics education; attitudes towards mathematics

\section{INTRODUCTION}

Issues and problems can be solved effectively through learning and improving structure of thought and intellectual competence. With the help of mathematics, one is showed that he can achieve desired results if certain correct steps are followed. Steps in solving mathematics problem help the process of reasoning and fortifies intellectual structure. Moreover, solving mathematics problem have been considered good for brain as it helps cognitive tasks such as decision making. Hence, learning mathematics is vital in education field and described as subject that is worth for this study.

Many students become fear and nervous of mathematics [1][2]. As a consequence, they are not only try to avoid any task involving mathematics, they are also did not take any math-related profession. This will limit their opportunities to earn and have a good future [3]. The result of this scenario has an effect of negative consequences at the national level as our nation now are highly dependent on technology [3]. Learning process should be enjoyable as to attract students' attention towards learning mathematics. Students who are enjoy in the class learning mathematics, they will be motivated and willing to put more effort to learn and consequently improve their achievement in mathematics [4]. Since attitudes towards mathematics have important roles in the process of learning, then it is still be focused of scholars to investigate factors and effect of the attitudes of the students.

To make students have positive attitude towards mathematics is very difficult and challenges to mathematics teacher [5]. Many negative emotions arise when students learn mathematics. Hence, mathematics teachers required to be cautious about student's affective belief [5] in learning mathematics. 
Preferences in mathematics, style of studying mathematics, classroom activities engagements and manymore will be affected if students' feelings and perception about mathematics are negative. It will be worst if this emotion affects the achievement of the students [6]. Therefore, teachers need to apply effective teaching style and employ innovations in learning as it can increase ability of thinking and improve positive beliefs of students.

There are many studies have been done to improve students' perception toward learning mathematics $[7,8,910,11]$. [7] have used sporting context in their study as they claimed the tasks are more enjoyable. They have used the game of Ki-o-rahi where most of the features involved in this game are from the aspect of measurement strand. Some of the examples in measurement strand are metric unit conversion, circumference, area, scale drawing, angles and many more. In a work done by [8] have implemented computer- assisted instruction (CAI) in studying mathematics. The effects of CAI on the attitude of students have been studied. They carried out the usage of CAI in four weeks. From the study, the researchers found that the usage of CAI have improved students' attitude towards mathematics compared to using traditional instruction. Learning level of students also are found to have increased. A recent research done by [9] have proposed of using problem posing approach to improve students' attitudes towards mathematics. They have collected data through observation, students answering questionnaires and test results given to the students. They have used observations about learning activities done by teachers and students using problem posing approach. Then they used questionnaire in order to identify students' attitude toward mathematics based on the determined indicators. Finally, they have used multiple choice questions for the students to answer in order to determine students' competency achievement and mastery learning. Based on the research done, they found that the students' behavior toward mathematics learning process have been improved. Another research done by [10] have proposed class practices through research activities. The activities are mathematical research activities based on problematic situation. The objectives of these activities are to give versatile working methods to the students in which students can compare arguments, intuitions and ideas in a collaborative manner. At the end, the researchers conclude that the activities have improved students' attitude towards mathematics. In a study done by11], they investigated the learning strategies that are conventional method, self and cooperative instructional whether they have an effect on attitude towards mathematics. From the study, they found that cooperative instructional have an effect on attitude towards mathematics and they have suggested that all mathematics teacher need to be trained to use self and cooperative learning strategies as these two have significant main effect on students' towards mathematics.

The aim of this paper is to present the results of a research on the teaching application of mathematics to the students. The research is made on 19 university students and it studies how students' beliefs about confidence in mathematics, importance of mathematics and engagement in mathematics before and after teaching application of mathematics to the students.

\section{METHODOLOGY}

A second year degree consisting of 19 students participated in this study. A program of Smart for Mathematics have been done to selected students of second year degree course from Computer Science Faculty. The students are from varieties of courses in Faculty of Computers Science which include Multimedia (BITM), Computer Game (BITE), Database (BITD), Software Engineering (BITS), Computer Security (BITZ), Network (BITC) and Artificial Intelligence (BITI). Out of 30 students selected for the program, only 19 students turn up. Smart for Mathematics program is a one-day program where the objective of the program is to enhance students' mathematics skills and to nurture positive attitudes towards mathematics. The program is designed where applications of mathematics in Computer Science have been exposed to the students. Teaching applications of mathematics in Computer Science include three subtopics that are applications of Calculus, Discrete Mathematics and Linear Algebra. Questionnaires about students' beliefs in confidence in mathematics, importance of mathematics and engagement in mathematics have been given to the students before teaching the applications of mathematics. These questionnaires have been adapted from [7]. Some of the question have been reviewed and only 20 statements have been used. This 20 statements include for all three components of attitude that are confidence in mathematics, importance 
in mathematics and engagement in mathematics. The questionnaires used a five point Likert Scale (Strongly Agree (5), Agree (4), Undecided (3), Disagree (2), Strongly Disagree (1)). Students answered the questions based on his/her agreement for each statement. The results of the questionnaires are considered as pre Smart for Mathematics. Then after teaching applications of mathematics, we gave the same set of questionnaires to the students and the results are considered as post - Smart for Mathematics. The results of pre - Smart for Mathematics was compared with the results of post - Smart for Mathematics. Some of the examples of teaching applications of mathematics are as follows.

\section{Applications of calculus in computer science}

Calculus is foundation of state-of-the-art mathematic and information industry. It has greatly affect the development of the computer as computer is a mathematical model that link binary system to complete calculation in mathematics [12]. Some of the applications are in image processing. Calculus is used in detection of edges in an image where the occurrence of edges shows boundaries of different regions. From the edges, important features such as curves, lines and corners can be obtained and be used computer vision algorithms for recognition. Another application of calculus is optimization. One of the optimization algorithms is gradient descent. Gradient descent is an algorithm that used for finding local minimum of a large dimensional space and it functions iteratively. It uses multivariate calculus and very useful in machine learning. In robotics, calculus is used to model physical movements of a robot. Knowledge like partial derivatives and gradients are used compute rotation speed and release angle.

\section{Applications of discrete mathematics in computer science}

Discrete mathematics is important to the study of computer science and it provides a foundation for the design and functionalities of software and hardware in digital computers. Some important topics in discrete mathematics are mathematical reasoning, set theory, algebraic structures, graphs and trees and combinatorics [13]. One of the applications of discrete mathematics in computer science is cryptography. Cryptography is the study on how to create passwords and security structures for computers. It is a study about encryption and decryption of plain text. Another application is in relational database. Relational database is important in tracking employees, clients and resources and connecting traits for each entity using concept of sets where information is grouped and organized. Logistics is another application of discrete mathematics. Logistic rely on graphs theory and graphs that help organizing the flow of information, goods and many more. The graphs can be analyzed and the best route for shipping can be determined.

\section{Applications of Linear Algebra in Computer Science}

Linear algebra is one of the required mathematics courses for students majoring in computer science and has significant role in many computer science applications. Some of the applications includes machine learning, graphics, computer vision, parallel computing, speech recognition and many more. One of the topic in linear algebra is matrices. Matrices in use heavily in computer graphics. Video gaming industry use computer graphics where the important foundation in program 3D video game is matrices. Matrices are used as tools to construct and manipulate a realistic animation of polygonal figure. In computer vision, linear algebra is used in rectification of images, tracking motion of a rigid body, transforming color spaces and many more. Information in social networks can also be represented in the form of matrices. Application of computer and mathematical tools using matrices can be used in order to find patterns and summarization. Matrices also can be used in cryptography. There are two matrices involve that is one matrix is used to encode, the encoding matrix and another matrix is used for decode, the decoding matrix. 


\section{RESULTS}

There are 20 statements which represent three components used that are confidence in mathematics, importance of mathematics and engagement in mathematics have been answered by the students. The analysis of the results had been done using R-Studio. Cronbach's alpha of 0.74 have been obtained to imply that the issue of reliability is not violated. There are positive statements and negative statements in each variable and these statements have been analyzed separately. The examples of positive statements are:

a. I get a great deal of satisfaction out of solving mathematics problem. - confidence in mathematics.

b. I believe studying mathematics help me with problem solving in other area. - importance of mathematics.

c. I am willing to take more than the required amount of mathematics. - engagement in mathematics.

The examples of negative statements are:

a. Mathematics makes me feel uncomfortable - confidence in mathematic.

b. When I hear the word mathematics, I have a feeling of dislike. - engagement in mathematics.

There are 19 students have answered the questionnaires and they are taking varieties of computer science course in Faculty of Computer Science. Figure 1 shows the bar plot for number of students based on their courses. There are 2 students who do not indicate his/her courses.

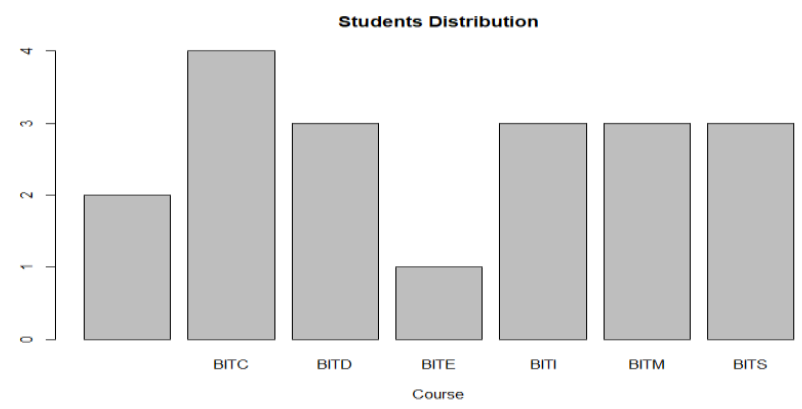

FIG. 1 Students' distribution based on their course

Based on the results of questionnaire given to the students, Table 1 shows the percentage of pre - Smart for Mathematics and post - Smart for Mathematics for component confidence in mathematics. We consider the frequency of students who have answered Agree (4) and Strongly Agree (5) only for positive statements and negative statements when calculating percentages.

Table 1 Percentage of pre - Smart for Mathematics and post - Smart for Mathematics for all three components confidence in attitude towards mathematics

\begin{tabular}{lll}
\hline \hline Confidence in Mathematics & Pre - Smart for Mathematics & Post - Smart for Mathematics \\
\hline Positive statements & $45.61 \%$ & $94.74 \%$ \\
Negative statements & $56.39 \%$ & $30.83 \%$ \\
Importance of Mathematics & Pre - Smart for Mathematics & Post - Smart for Mathematics \\
Positive statements & $67.37 \%$ & $86.32 \%$ \\
Negative statements & No negative statements & No negative statements \\
Engagement in Mathematics & Pre - Smart for Mathematics & Post - Smart for Mathematics \\
Positive statements & $31.58 \%$ & $65.79 \%$ \\
Negative statements & $45.61 \%$ & $19.30 \%$ \\
\hline
\end{tabular}


As we can see from Table I, percentage of students who are agree with positive statements have been increased in Post - Smart for Mathematics have been increased compared to Pre - Smart for Mathematics. The increment of percentage happened in confidence in mathematics, important of mathematics and as well as in engagement in mathematics. While for negative statements, the percentage of students who agree with negative statements have been decreased in Post - Smart for Mathematics compared to Pre - Smart for Mathematics. This shows that by teaching applications of mathematics, positive attitudes towards mathematics became higher. Students have widened their mind by looking the advantages of learning mathematics that can help them in doing well in some of the topics in computer science. The results also have been supported by doing hypothesis testing about the difference of median values in Likert scale for pre and post - Smart for Mathematics. Since the sample size is small and the data are not normally distributed, then we use nonparametric test Wilcoxon signed rank test to test the difference of medians in results of questionnaires.

\section{Positive statements:}

H0: Difference of medians is 0 (median of Pre-Smart for Mathematics is equals to median of Post- Smart for Mathematics)

H1: Difference of medians is $<0$ (median of Pre -Smart for Mathematics is less than median of Post- Smart for Mathematics)

Negative statements:

H0: Difference of medians is 0 (median of Pre-Smart for Mathematics is equals to median of Post- Smart for Mathematics)

H1: Difference of medians is $>0$ (median of Pre -Smart for Mathematics is greater than median of PostSmart for Mathematics)

Table 2 show the results of the test. From Table II, we can see that in all tests for positive and negative statements, the $p$-value $<0.05$. This indicate the difference in medians is not equals to zero and hence, we can conclude that by teaching applications of mathematics, the positive attitude towards mathematics have been increased significantly.

Table 2 Results of Wilcoxon signed rank test for positive statements and negative statements in confidence in mathematics, importance of mathematics and engagement in mathematic.

\begin{tabular}{cc}
\hline \hline Confidence in Mathematics & P-value from Wilcoxon signed rank test \\
\hline Positive statements & $\mathrm{p}$-value $=9.297 \mathrm{e}-05$ \\
Negative statements & $\mathrm{p}$-value $=0.004439$ \\
\hline $\begin{array}{c}\text { Importance of Mathematics } \\
\text { Positive statements }\end{array}$ & $\mathrm{p}$-value $=0.004446$ \\
\hline $\begin{array}{c}\text { Engagement in Mathematics } \\
\text { Positive statements }\end{array}$ & $\mathrm{p}$-value $=0.001445$ \\
Negative statements & $\mathrm{p}$-value $=0.0004958$ \\
\hline \hline
\end{tabular}

\section{DISCUSSION AND CONCLUSION}

The purpose of learning Mathematics is very important for the students to know. When we teach applications of mathematics in computer science for computer science students, their mind start to react positively and they know the purpose of learning mathematics. Previously, the students just accept mathematical theory and do not know the usage of learning mathematics. When the theory part become tougher, they tend to dislike mathematics and negative perceptions start to arise. To them, mathematics is just one difficult subject and they are compulsory to take the subject and just to have grade in the 
assessments throughout their study. The results of the study show that teaching applications of mathematics have made the students change their perception and this has increase the positive attitude towards mathematics.

\section{ACKNOWLEDGEMENTS}

Our deepest gratitude and thanks to Universiti Teknikal Malaysia Melaka (UTeM) and the Ministry of Higher Education Malaysia for funding this research grant under Short Term Research Grant (Grant no: S01629-PJP/2018/FTMK(2B)).

\section{REFERENCES}

[1] Mensah, J. K., Okyere, M., \& Kuranchie, A. (2013). Student attitude towards Mathematics and performance : Does the teacher attitude matter? Journal of Education and Practice, 4(3), 132-139

[2] Atan, M., \& Kasmin, F. (2017). TECHNICAL STUDENTS' ATTITUDE TOWARDS MATHEMATICS. In 4th International Conference on Educational Research and Practice

[3] Beilock, S. (2010). Math Anxiety. Science \& Children, 8-10. https://doi.org/10.1177/2372732215601438.

[4] Buckley, S. (2013). Deconstructing maths anxiety: Helping students to develop a positive attitude towards learning maths. Student Learning Processes. Retrieved from http://research.acer.edu.au/learning_processes/16

[5] Gafoor, K. A., \& Kurukkan, A. (2015). Why High School Students Feel Mathematics Difficult? An Exploration of Affective Beliefs. UGC Sponsored National Seminar on Pedagogy of Teacher Education- Trends and Challenges, (August), 1-6. Retrieved from http://files.eric.ed.gov/fulltext/ED560266.pdf

[6] Kibrislioglu, N. (2015). An Investigation About 6th Grade Students' Attitudes Towards Mathematics. Procedia - Social and Behavioral Sciences, 186, 64-69. https://doi.org/10.1016/j.sbspro.2015.04.024

[7] Sanchal, A., \& Sharma, S. (2017). Students' Attitudes Towards Learning Mathematics: Impact of Teaching in a Sporting Context. Teachers and Curriculum, 17(1), 89-99. Retrieved from https://files.eric.ed.gov/fulltext/EJ1149612.pdf

[8] Aliasgari, M., Riahinia, N., \& Mojdehavar, F. (2010). Computer-assisted instruction and student attitudes towards learning mathematics. Education, Business and Society: Contemporary Middle Eastern Issues, 3(1), 614. https://doi.org/10.1108/17537981011022779

[9] Vionita, A., \& Purboningsih, D. (2017). Improving attitudes toward mathematics learning with problem posing in class VIII. AIP Conference Proceedings, 1868. https://doi.org/10.1063/1.4995134

[10] Mammana, M. F., \& Pennisi, M. (2009). A class practice to improve student's attitude towards mathematics. Proceedings of the 10th International Conference "Models in Developing Mathematics Education', Dresden, Saxony, Germany, September 11--17, 2009., 395-398

[11] Ifamuyiwa, S. A., \& Akinsola, M. K. (2008). Improving senior secondary school students' attitude towards mathematics through self and cooperative-instructional strategies. International Journal of Mathematical Education in Science and Technology, 39(5), 569-585. https://doi.org/10.1080/00207390801986874

[12] Wing, J. M. (2002). Mathematics in Computer Science Curricula Prelude : Three Observations, (July)

[13] Garcia, O. V. (1985). Discrete mathematics computer science. IEEE Potentials, (February), 16-17 